Check for updates

Cite this: Chem. Sci., 2018, 9, 433

\title{
Origin of unusual spinel-to-layered phase transformation by crystal water $\dagger$
}

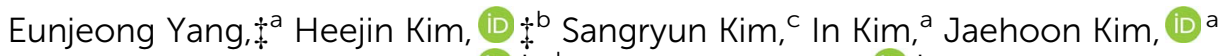 \\ Hyunjun Ji, ${ }^{a}$ Jang Wook Choi ${ }^{*}$ *ad and Yousung Jung (D) *a
}

It is well known that many layered transition metal oxides can transform into a spinel structure upon repeated battery cycling, but a phase transition in the opposite direction is rare. Recently, the transformation from spinel $\mathrm{Mn}_{3} \mathrm{O}_{4}$ to layered $\mathrm{MnO}_{2}$ was observed during the operation of a $\mathrm{Mg}$ battery in aqueous conditions, resulting in high performance $\mathrm{Mg}$ batteries. We hereby use $a b$ initio calculations to unveil the mechanism by which crystal water plays a critical role in this unique transformation. Once inserted into the spinel form, a water molecule donates an electron, offering a key structural and thermodynamic driving force to initiate the transformation process. These crystal water molecules then get favorably clustered into a planar form in the layered structure and act as a stabilizing agent for birnessite. Kinetically, the inserted crystal water dramatically promotes the necessary rearrangement of $\mathrm{Mn}$ during the transition by lowering the activation barrier by $>2 \mathrm{eV}$. The present structural, thermodynamic and kinetic understanding of the crystal water-driven phase transition provides novel insights to further the design of related low dimensional hydrated materials for multi-valent cathodes.

Received 20th September 2017
Accepted 24th October 2017

DOI: $10.1039 / \mathrm{c} 7 \mathrm{sc} 04114 d$

rsc.li/chemical-science insertion of $\mathrm{Li}, \mathrm{Na}$ or $\mathrm{Mg}$ into birnessites and the pseudocapacitive charge storage of birnessites have been investigated..$^{5-10}$

Recently, a birnessite cathode material was successfully synthesized from spinel $\mathrm{Mn}_{3} \mathrm{O}_{4}$ precursors using an electrochemical method. ${ }^{11,12}$ When typical electrochemical charge and discharge cycles were performed in aqueous electrolytes, the structural transformation of a 3-dimensional spinel to a 2dimensional birnessite, i.e. a spinel-to-layered transformation, was observed. Even though it has long been known that many layered TM oxides transform into a spinel structure, i.e. a layered-to-spinel transformation, upon repeated battery cycling, ${ }^{13-18}$ the phase transition in the opposite direction that takes place during the formation of birnessite is unusual. The main driving force for this spinel-to-layered structure conversion is suggested to be the insertion of crystal water on the basis of experimental data which showed that the phase transition occurs only when spinel $\mathrm{Mn}_{3} \mathrm{O}_{4}$ is cycled in aqueous electrolytes ${ }^{11,12,19}$ and that a higher water content in the compound resulted in a more efficient transformation into birnessite, ${ }^{\mathbf{2 0}}$ which makes this spinel-to-layered transformation even more peculiar. Additionally, $\mathrm{Na}$ - or Mg-containing birnessite shows improved capacity retention and rate capability over repeated battery cycling when compared to the anhydrous sample. ${ }^{\mathbf{1 0 , 2 1}}$ Such enhancements in the energy and power density due to structural water molecules have also been reported in tungsten oxides $^{22}$ and vanadium oxides. ${ }^{23}$ Even so, the beneficial effects of crystal water molecules in both enhancing the electrochemical performance and mediating the spinel-to-layered phase transition have not yet been fully understood.

\footnotetext{
${ }^{a}$ Graduate School of EEWS, Korea Advanced Institute of Science and Technology, 291 Daehak-ro, Daejeon, 34141, Republic of Korea. E-mail: ysjn@kaist.ac.kr

${ }^{b}$ Electron Microscopy Research Center, Korea Basic Science Institute, 169-148 Gwahak ro, Daejeon 34133, Republic of Korea

'Institute for Materials Research, Tohoku University, Sendai 980-8577, Japan

${ }^{d}$ School of Chemical and Biological Engineering, Institute of Chemical Processes, Seoul National University, 1 Gwanak-ro, Seoul 08826, Republic of Korea. E-mail: jangwookchoi@snu.ac.kr

$\dagger$ Electronic supplementary information (ESI) available: Calculation details, intercalation geometries, interlayer distance. See DOI: 10.1039/c7sc04114d

\$ These authors contributed equally to this work.
} 
Herein, in an effort to broaden our understanding of birnessites and the possibilities of similar hydrated materials as electrode materials, we investigate the spinel-to-birnessite transformation on the basis of first-principles calculations, focusing on the effect of crystal water on this structural transition.

\section{Results and discussion}

\section{Intercalation of crystal water and alkali ions}

The chemical formula of spinel $\mathrm{Mn}_{3} \mathrm{O}_{4}$, which belongs to the space group $\mathrm{I}_{1} / \mathrm{amd}$, can be rewritten as $\mathrm{Mn}^{2+} \mathrm{Mn}_{2}{ }^{3+} \mathrm{O}_{4}$, where the $\mathrm{Mn}^{2+}$ and $\mathrm{Mn}^{3+}$ cations occupy the tetrahedral and octahedral sites respectively (Fig. 1a). When we compared the stability of the octahedral and tetrahedral sites by removing one $\mathrm{Mn}$ atom from each site, tetrahedral Mn was less stable than octahedral Mn by $60 \mathrm{meV}$ per formula unit, this is consistent with experimental measurements in which $\mathrm{Mn}$ in the tetrahedral site was preferentially dissolved over the octahedral Mn. ${ }^{19}$ Crystallographically speaking, since the spinel structure shares the same close-packed oxygen framework as the layered structure, ${ }^{24}$ the phase transition between the two structures is fairly feasible without changing the oxygen stacking sequence. For this reason, it is well known that layered lithium manganese oxide $\left(\mathrm{Li}_{1-x} \mathrm{MnO}_{2}\right)$ spontaneously transforms to the spinel structure $\left(\mathrm{LiMn}_{2} \mathrm{O}_{4}\right)$ upon battery cycling, just by migrating the transition metal into the Li layer; ${ }^{\mathbf{1 3 2 5 , 2 6}}$ the phase transition that occurs when preparing birnessite is exactly the opposite process.

A scheme of the spinel-to-layered phase transition, with the help of crystal water molecules, is summarized in Fig. 1. According to recent studies on the electrochemical generation of $\mathrm{Mg}$ birnessite, the spinel-to-layered transition process is

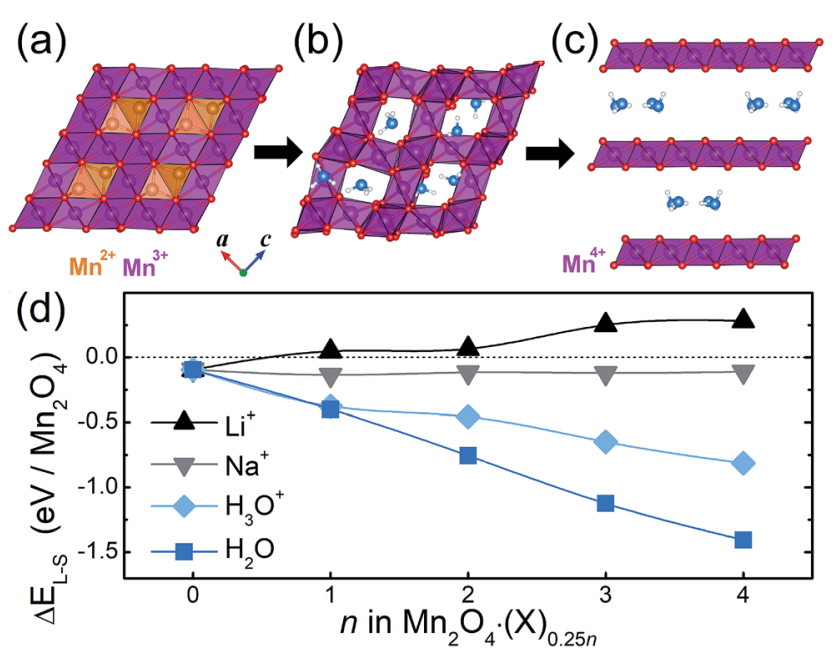

Fig. $1(\mathrm{a}-\mathrm{c}) \mathrm{A}$ scheme of the spinel-to-layered phase transition: (a) spinel $\mathrm{Mn}_{3} \mathrm{O}_{4}$, (b) water intercalated $\mathrm{Mn}_{2} \mathrm{O}_{4}$ after the $\mathrm{Mn}^{2+}$ dissolution, (c) transformed layered $\mathrm{Mn}_{2} \mathrm{O}_{4}$ with interlayer $\mathrm{H}_{2} \mathrm{O}$ molecules. The blue and white spheres are the $\mathrm{O}$ and $\mathrm{H}$ of the crystal water, respectively. $\mathrm{Mn}^{2+}$ cations are orange and the purple octahedrons are the $\mathrm{Mn}_{2} \mathrm{O}_{4}$ framework. (d) The stability of the layered structure relative to that of the spinel structure, defined as $\Delta E_{\mathrm{L}-\mathrm{S}}=E_{\text {Layered }}-E_{\text {Spinel }}$ for $\mathrm{Mn}_{2} \mathrm{O}_{4} \cdot(\mathrm{X})_{0.25 n}$, where $\mathrm{X}=\mathrm{H}_{2} \mathrm{O}, \mathrm{H}_{3} \mathrm{O}^{+}$, $\mathrm{Li}^{+}$or $\mathrm{Na}^{+}$. initiated by the dissolution of $\mathrm{Mn}^{2+}$ from the spinel $\mathrm{Mn}_{3} \mathrm{O}_{4}$ (Fig. 1a), ${ }^{20}$ which leaves the chemical composition of the spinel compound as $\mathrm{Mn}_{2} \mathrm{O}_{4}$. The water molecules then intercalate into the vacant space in the remaining $\mathrm{Mn}_{2} \mathrm{O}_{4}$ framework (Fig. 1b). During this intercalation of water molecules and subsequent phase transition, the tetrahedral sites and the octahedral sites between them play an important role, since they can potentially accommodate diverse guest species and they also sit in the ionic migration channel required for the phase transition. Here, we considered $\mathrm{H}_{2} \mathrm{O}$ and $\mathrm{H}_{3} \mathrm{O}^{+}$as the intercalation form of crystal water, since it is suggested they both participate in the overall phase transition process on the basis of thermal and electron microscopy analyses. That is, albeit there is a low concentration of $\mathrm{H}_{3} \mathrm{O}^{+}$under neutral $\mathrm{pH}$ conditions, its insertion into the spinel structure is detected, while the final form of crystal water in the layered birnessite is $\mathrm{H}_{2} \mathrm{O}{ }^{19}$

From extensive calculations, we found that at most one water molecule can be intercalated into the $\mathrm{Mn}_{2} \mathrm{O}_{4}$ spinel framework without disrupting the structure, which corresponds to the chemical composition $\mathrm{MnO}_{2} \cdot(\mathrm{X})_{0.5}$, where $\mathrm{X}=\mathrm{H}_{2} \mathrm{O}$ or $\mathrm{H}_{3} \mathrm{O}^{+}$. Detailed intercalation geometries are presented in Fig. S1 (ESI). $\dagger$ Once inserted, the $\mathrm{H}$ atom of the water molecule $\left(\mathrm{H}^{\mathrm{W}}\right)$ forms $\mathrm{O}-\mathrm{H}^{\mathrm{w}}$ bonds with the $\mathrm{O}$ atoms of the spinel framework, where the $\mathrm{O}-\mathrm{H}^{\mathrm{w}}$ distance is $1.30-1.57 \AA$. Thus the $\mathrm{O}$ atom of the water molecule $\left(\mathrm{O}^{\mathrm{w}}\right)$ is placed off-center in the tetrahedron or octahedron as shown in Fig. $1 \mathrm{~b}$ and S1. $\dagger$ In this stage, the framework is still securely sustained by the octahedral Mn pillars, leaving the interplanar distance of the (101) plane to be 4.8-5.2 A regardless of the water content (Fig. S2†). This interplanar distance is consistent with the experimental value. ${ }^{19}$ Lastly, the inserted crystal water promotes the phase transformation from the spinel to the layered structure with an increased (101) interplanar distance of $7.27 \AA$ for $\mathrm{X}=\mathrm{H}_{2} \mathrm{O}$ (Fig. 1c), the crystal water molecules are located in the center of the interlayer space as experimentally observed..$^{12,20}$ In the birnessite, the interlayer distance for $\mathrm{X}=\mathrm{H}_{3} \mathrm{O}^{+}(6.77 \AA)$ is quite a bit smaller than the observed value $(7.2 \AA),{ }^{20}$ confirming that the final form of crystal water in the birnessite is $\mathrm{H}_{2} \mathrm{O}$.

In order to investigate whether this water-inserted spinel phase thermodynamically favors the formation of the birnessite structure, we evaluated the energy difference between the spinel (Fig. 1b) and layered (Fig. 1c) $\mathrm{Mn}_{2} \mathrm{O}_{4} \cdot(\mathrm{X})_{0.25 n}$ structures, defined as $\Delta E_{\mathrm{L}-\mathrm{S}}=E_{\text {Layered }}-E_{\text {Spinel }}$, where $E_{\text {Layered }}$ and $E_{\text {Spinel }}$ correspond to the calculated total energy of each structure. The calculated $\Delta E_{\mathrm{L}-\mathrm{S}}$ values, when varying $n$ from 0 to 4 in $\mathrm{Mn}_{2} \mathrm{O}_{4}$. $(\mathrm{X})_{0.25 n}$, are compared in Fig. $1 \mathrm{~d}$ for $\mathrm{X}=\mathrm{H}_{2} \mathrm{O}, \mathrm{H}_{3} \mathrm{O}^{+}, \mathrm{Li}^{+}$and $\mathrm{Na}^{+}$. Here, we assumed that all systems are neutral since the reaction is electrochemical and the electrons are supplied externally for charge neutrality. It is noted that the systems containing crystal water molecules, i.e. $\mathrm{X}=\mathrm{H}_{2} \mathrm{O}$ or $\mathrm{H}_{3} \mathrm{O}^{+}$, have a thermodynamic driving force (negative $\Delta E_{\mathrm{L}-\mathrm{S}}$ values) for the transformation into the layered or birnessite structure. Moreover, the degree of preference for the layered form increases as the amount of water molecules $(n)$ in the compound increases. This is in good agreement with a previous experimental report suggesting that a higher crystal water content promotes an efficient phase transition into birnessite. ${ }^{\mathbf{2 0}}$ In the same literature, it was also 
pointed out that preventing the insertion of alkali ions facilitates the spinel-to-layered transformation and this is consistent with the present result, which indicates that the $\Delta E_{\mathrm{L}-\mathrm{S}}$ values for $\mathrm{X}=\mathrm{Li}$ and $\mathrm{Na}$ are close to zero or even positive (no thermodynamic driving force for such a phase transition). In addition, the calculated energetic preference for a layered structure increases in the order of $\mathrm{Li}<\mathrm{Na}<\mathrm{H}_{3} \mathrm{O}^{+}<\mathrm{H}_{2} \mathrm{O}$ insertion, which is identical to the order of increasing degree of the spinel-tobirnessite phase transformation observed in experiments. ${ }^{20}$

\section{Interaction between the crystal water and Mn framework}

First of all, as presented in Fig. 1c and 2a, we found that $\mathrm{H}_{2} \mathrm{O}$ molecules in the layered structure form a planar water cluster. According to a previous study, the growth of a small water cluster is favored by enthalpy, while it is unfavored by entropy; thus, at an ambient temperature where the entropic term is significant, the development of water clusters was exothermic. ${ }^{27}$ This result suggests that a $2 \mathrm{D}$ confined space, like our interlayer space, can constrain the motion of water and thus can promote the formation of water clusters. Recently, square-like ice was observed in graphene nanocapillaries, in which the authors propose that such clusters could develop in general when a $2 \mathrm{D}$ confined space is hydrophobic, ${ }^{28,29}$ since too strong an interaction between the wall and water can hinder the clustering of water. The latter point suggests that, in our layered system, the interaction between $\mathrm{H}_{2} \mathrm{O}$ and the layered $\mathrm{Mn}_{2} \mathrm{O}_{4}$ framework is as small as the one in a hydrophobic channel. Indeed, in the layered $\mathrm{Mn}_{2} \mathrm{O}_{4} \cdot\left(\mathrm{H}_{2} \mathrm{O}\right)$, the interaction energy between $\mathrm{H}_{2} \mathrm{O}$ and the framework is only $0.015 \mathrm{eV}$ per $\mathrm{H}_{2} \mathrm{O}$, whereas the interaction among $\mathrm{H}_{2} \mathrm{O}$ molecules is $0.41 \mathrm{eV}$ per $\mathrm{H}_{2} \mathrm{O}$. This weak interaction between $\mathrm{H}_{2} \mathrm{O}$ and the framework is also reflected in the long distance and marginal charge transfer between them, as shown in Fig. $2 b$.

On the other hand, crystal water molecules in the spinel $\mathrm{Mn}_{2} \mathrm{O}_{4} \cdot(\mathrm{X})_{0.25 n}$ interact strongly with the spinel framework and reduce the $\mathrm{Mn}$. In the case of $\mathrm{X}=\mathrm{H}_{3} \mathrm{O}^{+}$, intercalated hydronium molecules form a $\mathrm{O}-\mathrm{H}^{\mathrm{w}}$ bond (distance of $1.3 \AA$ ) with a nearby $\mathrm{MnO}_{6}$ polyhedron, in which the corresponding electron for charge neutrality reduces the $\mathrm{Mn}$ from $4+$ to $3+$ in the $\mathrm{Mn}_{2} \mathrm{O}_{4}$ framework. Surprisingly, we found that the inserted neutral $\mathrm{H}_{2} \mathrm{O}$ molecule also reduces the $\mathrm{Mn}_{2} \mathrm{O}_{4}$ framework by donating electrons. In the latter case, each of the $\mathrm{MnO}_{6}$ polyhedra is surrounded by $\mathrm{H}_{2} \mathrm{O}$ molecules with an $\mathrm{O}-\mathrm{H}^{\mathrm{w}}$ bond length of $1.57 \AA$ (Fig. 2c); this value is in between those of typical covalent $(\sim 1 \AA)$ and hydrogen $(\sim 2 \AA)$ bonds, which reflects that the charge transfer between the framework and $\mathrm{H}_{2} \mathrm{O}$ is substantial. When compared to isolated $\mathrm{H}_{2} \mathrm{O}$ molecules, each $\mathrm{H}_{2} \mathrm{O}$ in the spinel structure donates approximately 0.2 electrons to the interacting $\mathrm{MnO}_{6}$ units and as a result, $\mathrm{Mn}$ atoms in the framework accept electrons from the water molecules and thus are reduced.

This charge transfer between $\mathrm{H}_{2} \mathrm{O}$ and the framework can be seen clearly from the projected density of states (PDOS) of the $\mathrm{O}^{\mathrm{w}}-2 \mathrm{p}$ and $\mathrm{Mn}-3 \mathrm{~d}$ states of the spinel and layered compounds (Fig. 2d-f). The single point calculation with a PBE0 functional $^{30,31}$ is employed for drawing the PDOS using GGA $+\mathrm{U}$ (a)

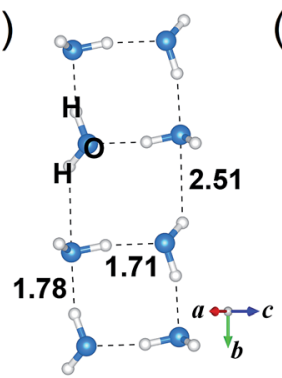

(b) Layered

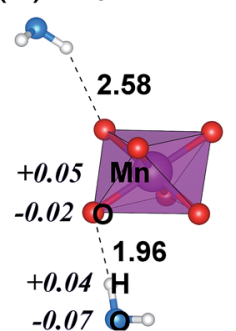

(c) Spinel

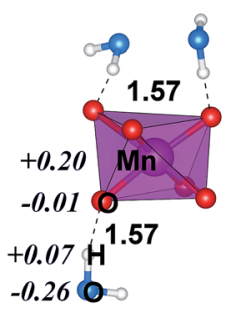

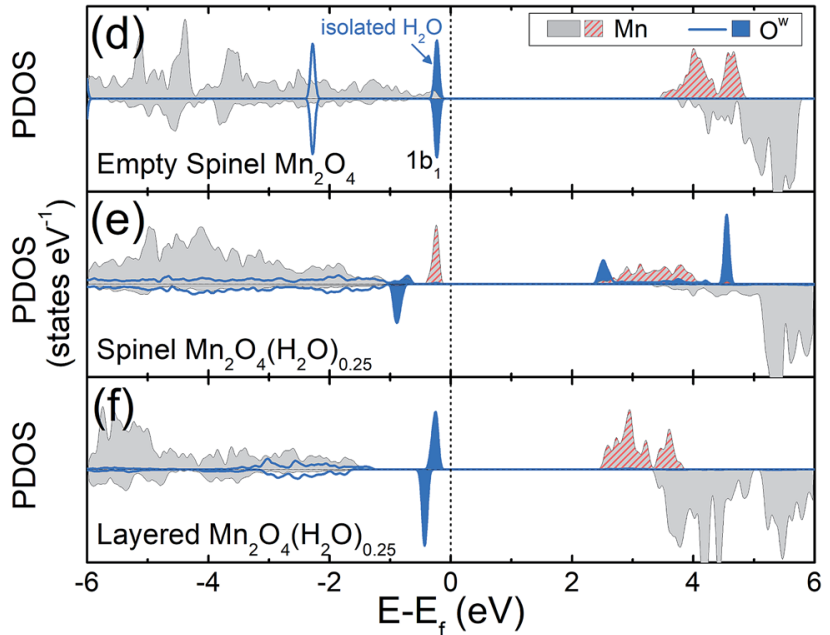
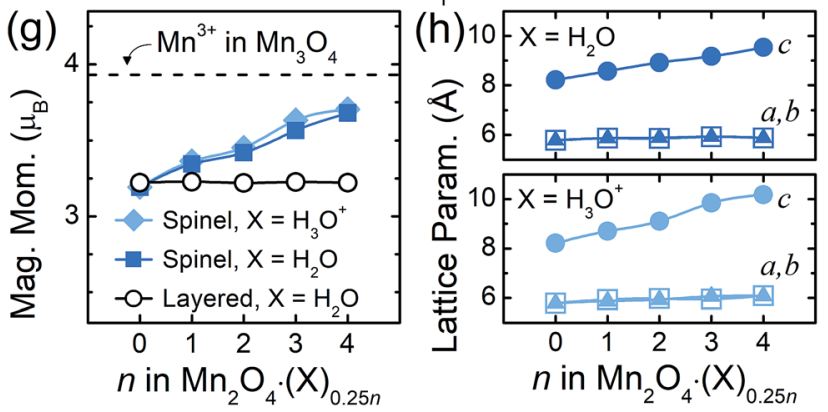

Fig. 2 (a) A water cluster formed in the layered $\mathrm{Mn}_{2} \mathrm{O}_{4} \cdot\left(\mathrm{H}_{2} \mathrm{O}\right)$. The numbers next to the dotted lines in bold denote the distance. (b and $c$ ) $\mathrm{MnO}_{6}$ octahedra and nearby crystal water molecules for the (b) layered and (c) spinel $\mathrm{Mn}_{2} \mathrm{O}_{4} \cdot\left(\mathrm{H}_{2} \mathrm{O}\right)$. The italicized numbers are the variation in charge density and the unitalicized numbers are bond distances. The charge densities are integrated by the Bader method. (d-f) The PDOS of (d) empty spinel $\mathrm{Mn}_{2} \mathrm{O}_{4}$, (e) spinel $\mathrm{Mn}_{2} \mathrm{O}_{4} \cdot\left(\mathrm{H}_{2} \mathrm{O}\right)_{0.25}$ and (f) layered $\mathrm{Mn}_{2} \mathrm{O}_{4} \cdot\left(\mathrm{H}_{2} \mathrm{O}\right)_{0.25}$. The upper and lower halves of each panel are spin up (majority) and down, respectively. The isolated $\mathrm{H}_{2} \mathrm{O}$ is presented together in (d). (g) The magnetic moments of $M n$ in the spinel and layered $\mathrm{Mn}_{2} \mathrm{O}_{4} \cdot(\mathrm{X})_{0.25 n}$. The value for $\mathrm{Mn}^{3+}$ in $\mathrm{Mn}_{3} \mathrm{O}_{4}$ (3.93) is presented with a dashed line for comparison. (h) The change in lattice parameters in spinel $\mathrm{Mn}_{2} \mathrm{O}_{4} \cdot(\mathrm{X})_{0.25 n}$.

geometries. The highest occupied molecular orbital (HOMO) of an isolated water molecule is $1 b_{1}$ as denoted by the blue area in Fig. 2d. When water is inserted into the spinel $\mathrm{Mn}_{2} \mathrm{O}_{4}$ (Fig. 2e), the $1 b_{1}$ orbital loses most of its spin up electrons, resulting in a significant number of unoccupied states above the Fermi level. The electron density of the isosurfaces (Fig. S3†) confirm that these unoccupied $\mathrm{O}^{\mathrm{w}}$ states are originally $1 \mathrm{~b}_{1}$ orbitals. In contrast, the layered $\mathrm{Mn}_{2} \mathrm{O}_{4} \cdot\left(\mathrm{H}_{2} \mathrm{O}\right)_{0.25}$ does not show such a drastic oxidation of water molecules (Fig. 2f). Furthermore, 
the empty spinel $\mathrm{Mn}_{2} \mathrm{O}_{4}$ has an antibonding orbital at the lowest unoccupied state which is composed of Mn spin up (see the crystal orbital Hamilton population ${ }^{32}$ in Fig. S4†). This antibonding orbital shifts below the Fermi level when crystal water is inserted (red hatching in Fig. 2e), indicating that the $\mathrm{Mn}$ is reduced by the crystal water insertion. Therefore, the evidence from the PDOS clearly points to a conclusion that a charge transfer, from the crystal water to $\mathrm{Mn}$ in the spinel structures, causes the reduction of $\mathrm{Mn}$. We note, from the methodological point of view, that the GGA + U functional gives essentially the same charge transfer results as PBE0, as shown in Fig. S5.†

The change in oxidation state of Mn caused by the insertion of crystal water can be more evidently seen from the magnetic moment that is proportional to the number of unpaired electrons. Fig. $2 \mathrm{~g}$ displays the net magnetic moments of $\mathrm{Mn}_{2} \mathrm{O}_{4}$. $(\mathrm{X})_{0.25 n}$ compounds with the spinel and layered structures. We note that the net magnetic moments are generally underestimated in oxide materials since electrons are polarized/ delocalized from the metal center to neighboring oxygen. ${ }^{33,34}$ When there is no crystal water $(n=0)$, the magnetic moments are around 3.2 for all the Mn structures regardless of the crystal structure, and these values are close to the number of unpaired electrons for $\mathrm{Mn}^{4+}$, which is 3 . However, when $n>0$ (i.e. with crystal water molecules), the magnetic moments have different values depending on which structure the $\mathrm{Mn}_{2} \mathrm{O}_{4} \cdot(\mathrm{X})_{0.25 n}$ takes. For the spinel structure, when $n=4$ for example, the average magnetic moment of $\mathrm{Mn}$ increases to 3.68 and 3.70 for $\mathrm{X}=\mathrm{H}_{2} \mathrm{O}$ and $\mathrm{H}_{3} \mathrm{O}^{+}$, respectively; this implies that $\mathrm{Mn}$ atoms in these compounds were reduced toward the $3+$ state due to the crystal water molecules. For the layered $\mathrm{Mn}_{2} \mathrm{O}_{4} \cdot\left(\mathrm{H}_{2} \mathrm{O}\right)_{0.25 n}$, on the other hand, the magnetic moments of all the Mn species have the same value (3.2) for all $n$, indicating that the oxidation state of $\mathrm{Mn}^{4+}$ in the layered compound remains unchanged with varying crystal water content; this result is attributed to the negligible interaction between the framework and crystal water in the layered structure as discussed above. As a result of the reduction of $\mathrm{Mn}$ from $4+$ to $\sim 3+$ in the presence of water molecules, the cell parameters of the spinel $\mathrm{Mn}_{2} \mathrm{O}_{4} \cdot(\mathrm{X})_{0.25 n}$ compounds increase anisotropically (Fig. 2h) since the $\mathrm{Mn}^{3+}$ state is susceptible to a Jahn-Teller distortion. We note that the change in the distance between the (101) planes is marginal (less than $0.2 \AA)$, as observed experimentally, ${ }^{10}$ since the Jahn-Teller distortion arises along the $c$-direction and this leads to a sliding of the Mn layers. The distortion index $(D)$, defined by Baur, ${ }^{35}$ also supports the reduction of the $\mathrm{Mn}$ center: the $D$ value of the spinel $\mathrm{Mn}_{2} \mathrm{O}_{4} \cdot(\mathrm{X})_{1.0}$ is 0.035 and 0.067 for $\mathrm{X}=\mathrm{H}_{2} \mathrm{O}$ and $\mathrm{H}_{3} \mathrm{O}^{+}$, respectively, which are between that of the $\mathrm{Mn}^{3+}$ case $(0.074$ in $\mathrm{Mn}_{3} \mathrm{O}_{4}$ ) and $\mathrm{Mn}^{4+}$ case (0.002 in layered $\left.\mathrm{Mn}_{2} \mathrm{O}_{4} \cdot\left(\mathrm{H}_{2} \mathrm{O}\right)_{1.0}\right)$.

\section{Thermodynamic contributions to the phase transition}

On the basis of these analyses of the interaction between crystal water and the Mn framework, the increasing stability of the layered structure upon water intercalation can be further understood by breaking down the energetics into the contributions from the framework and crystal water. For that, we evaluated the single point energy of the $\mathrm{Mn}_{2} \mathrm{O}_{4}$ framework and intercalated $\mathrm{X}$ molecules, whose geometries were taken from $\mathrm{Mn}_{2} \mathrm{O}_{4} \cdot(\mathrm{X})_{0.25 n}$. Then we compared their energies to those of the initial $\mathrm{Mn}_{2} \mathrm{O}_{4}$ framework (single point energy of the $\mathrm{Mn}^{2+}$ dissolved structure taken from $\mathrm{Mn}_{3} \mathrm{O}_{4}$ ) and geometry-optimized isolated $\mathrm{X}$ molecules, which are referenced as zero in Fig. 3a and b, respectively. While the crystal water is $\mathrm{H}_{2} \mathrm{O}$ in the transformed birnessite, its initial form can be both $\mathrm{H}_{2} \mathrm{O}$ and $\mathrm{H}_{3} \mathrm{O}^{+}$in the spinel as discussed above; thus we compared the layered $\mathrm{Mn}_{2} \mathrm{O}_{4} \cdot\left(\mathrm{H}_{2} \mathrm{O}\right)_{0.25 n}$, spinel $\mathrm{Mn}_{2} \mathrm{O}_{4}$. $\left(\mathrm{H}_{2} \mathrm{O}\right)_{0.25 n}$ and spinel $\mathrm{Mn}_{2} \mathrm{O}_{4} \cdot\left(\mathrm{H}_{3} \mathrm{O}^{+}\right)_{0.25 n}$ structures. Overall, it is clear that the spinel and layered phases exhibit entirely opposite behaviors. The spinel structure is destabilized predominantly due to the framework distortion, while the stability of the water molecules in it remains the same regardless of water content. In contrast, the framework stability of the layered structure is almost unaffected by the insertion of crystal water, but the stability of the intercalated water molecules substantially increases with increasing water content. These phenomena observed in Fig. 3a and $b$ are essentially driven by the crystal water, which will be discussed below.

In Fig. 3a, the $\mathrm{Mn}_{2} \mathrm{O}_{4}$ frameworks of the structures that contain water molecules are more stable (negative $y$ values) when compared to the initial $\mathrm{Mn}_{3} \mathrm{O}_{4}$ compound (dotted zero line). The empty $\mathrm{Mn}_{2} \mathrm{O}_{4}$ framework $(n=0)$ is the most stable since it is the relaxed geometry at a given $\mathrm{Mn}_{2} \mathrm{O}_{4}$ composition. With an increasing water content in the spinel crystal $(n)$, more $\mathrm{Mn}$ reduces from $4+$ to $3+$, where the former and latter are Jahn-Teller inactive and active species, respectively; this enlarged distortion during the redox reaction imposes a substantial energy penalty and thus destabilizes the spinel system. For the same reason, the
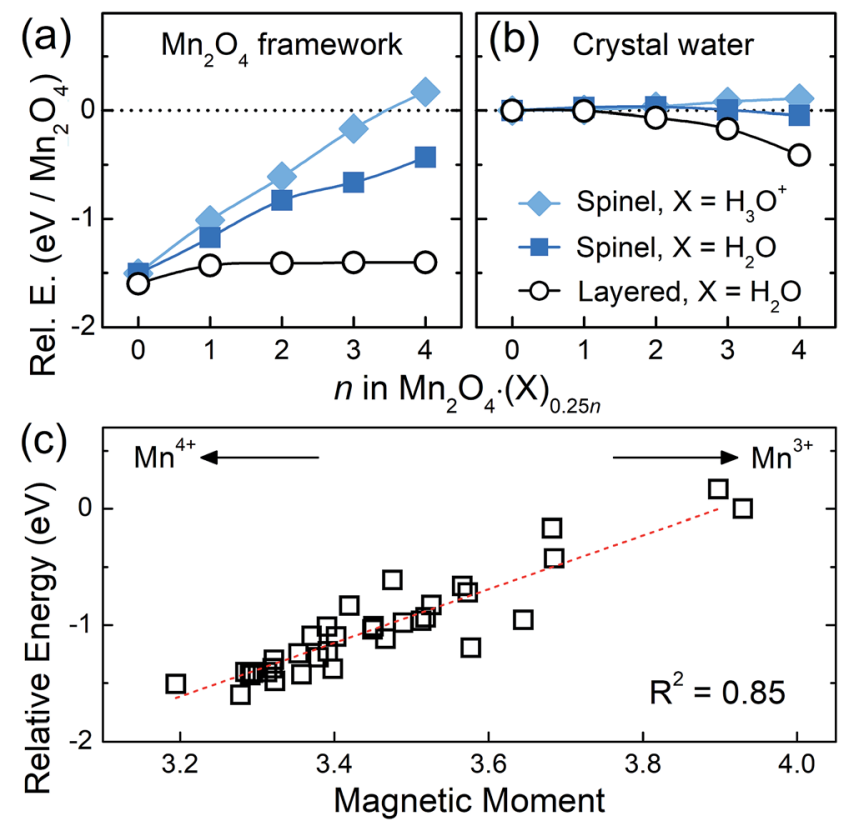

Fig. 3 The relative energies of the (a) $\mathrm{Mn}_{2} \mathrm{O}_{4}$ frameworks and (b) crystal water molecules for each composition of spinel and layered $\mathrm{Mn}_{2} \mathrm{O}_{4} \cdot(\mathrm{X})_{0.25 n}$. (c) The correlation between the magnetic moment of the $\mathrm{Mn}$ center that indicates its oxidation state and the relative energy of the $\mathrm{Mn}_{2} \mathrm{O}_{4}$ framework. A more negative $y$ value indicates a more stable structure. 
$\mathrm{Mn}_{2} \mathrm{O}_{4}$ framework of the initial $\mathrm{Mn}_{3} \mathrm{O}_{4}$ is the most unstable, since all the framework $\mathrm{Mn}$ atoms are $\mathrm{Mn}^{3+}$ in $\mathrm{Mn}_{3} \mathrm{O}_{4}$. When we draw the relative stability of the $\mathrm{Mn}_{2} \mathrm{O}_{4}$ framework versus the oxidation state of Mn for all the structures considered in this work (a total of 35 frameworks as described in the ESI $\dagger$ ), a linear correlation is reasonably clear $\left(R^{2}=0.85\right)$, supporting the idea that this destabilization is caused by $\mathrm{Mn}^{3+}$. In the $\mathrm{Mn}_{3} \mathrm{O}_{4}$, spinel $\mathrm{Mn}_{2} \mathrm{O}_{4} \cdot(\mathrm{X})_{0.25 n}$ and layered $\mathrm{Mn}_{2} \mathrm{O}_{4} \cdot\left(\mathrm{H}_{2} \mathrm{O}\right)_{0.25 n}$ structures, the $\mathrm{Mn}$ atoms that compose the $\mathrm{Mn}_{2} \mathrm{O}_{4}$ framework have the oxidation state of 3+, 3$4+$ (between $3+$ and $4+$ ) and $4+$, respectively, as identified in oxidation state analyses. Therefore, the overall stability of the framework, which is inversely proportional to the number of $\mathrm{Mn}^{3+}$, is in the increasing order of $\mathrm{Mn}_{3} \mathrm{O}_{4}<$ spinel $\mathrm{Mn}_{2} \mathrm{O}_{4^{-}}$ $\cdot(\mathrm{X})_{0.25 n}<$ layered $\mathrm{Mn}_{2} \mathrm{O}_{4} \cdot\left(\mathrm{H}_{2} \mathrm{O}\right)_{0.25 n}$. This stabilization of the layered framework results in the primary driving force for the spinel-to-layered phase transition. We note that $\mathrm{Li}$ and $\mathrm{Na}$ inside the spinel can also reduce the $\mathrm{Mn}$ center. However, unlike $\mathrm{H}_{2} \mathrm{O}$, the $\mathrm{Li}$ or $\mathrm{Na}$ reduces the $\mathrm{Mn}$ to $3+$ in the layered counterpart as well, due to its high ionicity. Therefore, the stability of the layered form with $\mathrm{Li}$ or $\mathrm{Na}$ is lower than the stability of the same structure with $\mathrm{H}_{2} \mathrm{O}$, leading to a smaller net thermodynamic driving force for the transition to a layered phase as shown in Fig. 1d.

In Fig. 3b, strong water-water interactions are observed in the layered structure with increasing water content, due to the aforementioned clustering of water molecules. This leads to charge reallocation within crystal water clusters, while the charge transfer between the layered $\mathrm{Mn}_{2} \mathrm{O}_{4}$ framework and $\mathrm{H}_{2} \mathrm{O}$ molecules is marginal ( 0.03 electrons as shown in Fig. $2 \mathrm{~b}$ ) and thus, once transformed to the $2 \mathrm{D}$ birnessite, the layered framework is almost unaffected by the amount of $\mathrm{H}_{2} \mathrm{O}$ insertion, as shown in Fig. 3a. To summarize, the crystal water itself contributes to the stability of the layered structure by clustering; but, in addition, it destabilizes the spinel framework by chemically reducing the Mn of the spinel structure, providing a thermodynamic driving force for the transition to layered birnessite.

\section{Kinetic role of crystal water in the phase transition}

Lastly, in order to investigate the effect of crystal water on the spinel-to-layered transition from a kinetic perspective, we evaluated the energy barriers for $\mathrm{Mn}$ migration in spinel $\mathrm{Mn}_{2} \mathrm{O}_{4}$ $\cdot(\mathrm{X})_{0.25 n}$ with and without crystal water molecules. The results are depicted in Fig. $4 \mathrm{a}$ and b. Since the phase transition requires part of the $\mathrm{Mn}$ in the $\mathrm{Mn}_{2} \mathrm{O}_{4}$ framework to be rearranged, a single $\mathrm{Mn}$ atom in the spinel framework was migrated from one octahedral site to another through the nearest tetrahedral site, so that a reverse procedure of the known layered-to-spinel transformation can be modelled. When there is no crystal water in the system ( $n=0$; empty), the calculated activation barrier for Mn migration is $3.27 \mathrm{eV}$. This energy barrier is reduced significantly to $1.20 \mathrm{eV}(1.12 \mathrm{eV})$ in the presence of $\mathrm{H}_{2} \mathrm{O}\left(\mathrm{H}_{3} \mathrm{O}^{+}\right)$ molecules, indicating that the crystal water greatly assists the diffusion of Mn for structural transformations.

The above results can be explained by understanding the structural and electronic aspects of the material. First, the lattice parameters and cell volume are overall expanded with the
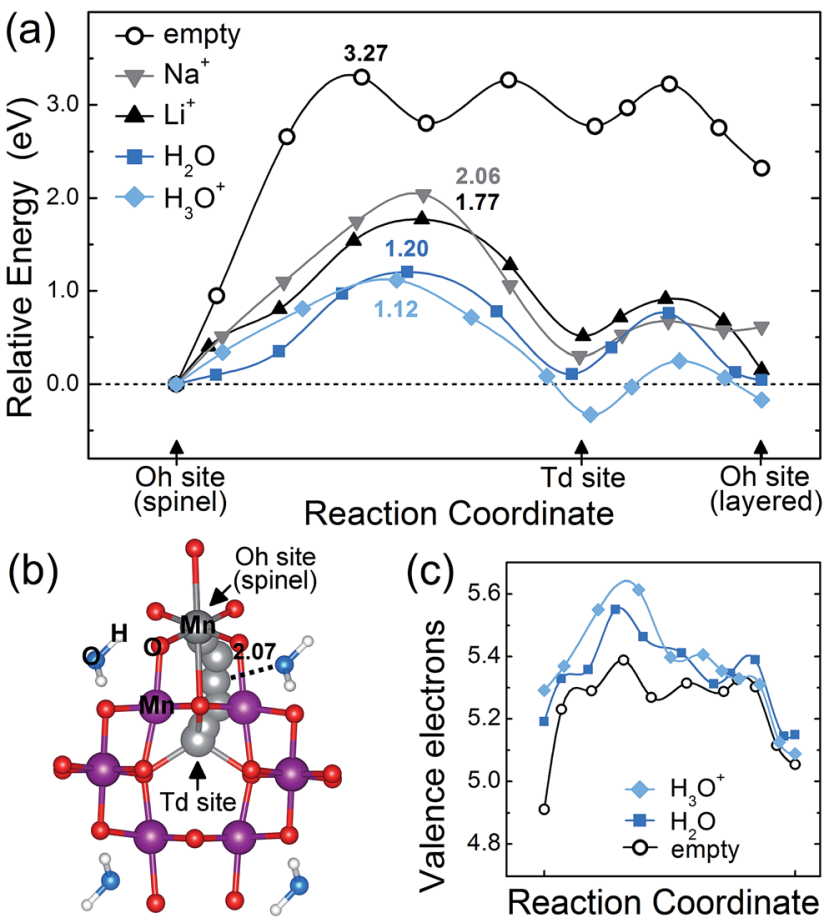

Fig. 4 (a) The calculated energy barriers for $M n$ migration in spinel $\mathrm{Mn}_{2} \mathrm{O}_{4} \cdot(\mathrm{X})_{0.25 n}$ for $n=0$ (empty) and $n=2\left(\mathrm{X}=\mathrm{Na}^{+}, \mathrm{Li}^{+}, \mathrm{H}_{2} \mathrm{O}\right.$ and $\mathrm{H}_{3} \mathrm{O}^{+}$). The numbers are migration barriers. (b) The traveling pathway of target $\mathrm{Mn}$ (gray sphere) from an Oh site to a Td site in the presence of crystal water. The number denotes a distance. (c) The charge density of the traveling $\mathrm{Mn}$ at each intermediate migration position.

insertion of water as shown in Fig. 2h, which enlarges the diffusion channel for Mn migration. Second, Mn atoms have 4+ oxidation states without crystal water, whereas they are in $\sim 3+$ states with crystal water. The electron density analysis (Fig. 4c) clearly shows that the presence of water molecules leads to a higher electron density (reduced oxidation state) for the traveling Mn atom, which decreases the electrostatic repulsion from neighboring atom centers more effectively. Third, the Mn migration process without the presence of water generates 1-3 broken bonds and the corresponding partially unpaired electrons destabilize the system. When intercalated species such as crystal water and alkali ions are in the framework, however, the water or alkali ions can stabilize the intermediate Mn states with broken bonds by accepting some of their unpaired electrons, and thus reduce the migration barrier. Due to these aspects, the intercalated $\mathrm{Na}$ and $\mathrm{Li}$ ions, despite their positive charge, also decrease the Mn migration barrier to 2.06 and $1.77 \mathrm{eV}$, respectively, although they are less effective than crystal water. When examining the Mn migration pathway in Fig. 4 b, the traveling $\mathrm{Mn}$ inclines toward a water molecule and makes a Mn$\mathrm{O}^{\mathrm{w}}$ bond with a distance of $2.07 \AA$. This partially-bonded intermediate state, which is not observed in the cases with $\mathrm{Li}$ or $\mathrm{Na}$ inserted (Fig. S6†), additionally lowers the Mn migration barrier.

\section{Conclusions}

We revealed the underlying mechanism of how crystal water plays an essential role in the unusual spinel-to-layered phase 
transformation that takes place during the electrochemical cycling of $\mathrm{Mn}_{3} \mathrm{O}_{4}$ in aqueous media. We found that spinel $\mathrm{Mn}_{3} \mathrm{O}_{4}$ compounds energetically prefer a layered structure after $\mathrm{Mn}^{2+}$ dissolution when crystal water is present. Electronically, the inserted crystal water destabilizes the spinel $\mathrm{Mn}_{2} \mathrm{O}_{4}$ framework by reducing $\mathrm{Mn}^{4+}$ to distortive $\mathrm{Mn}^{3+}$, whereas only a weak interaction between crystal water and layered $\mathrm{Mn}_{2} \mathrm{O}_{4}$ exists, leaving $\mathrm{Mn}$ as stable $\mathrm{Mn}^{4+}$ in the layered framework. Instead, water molecules form a planar cluster in the $2 \mathrm{D}$ confined space of the layered structure, further stabilizing the layered phase compared to the spinel phase, in which such water clustering is not feasible. This difference in water-framework interactions between the spinel and layered phases provides a key structural and thermodynamic driving force for the experimentally observed spinel-to-layered transition. Kinetically, the crystal water considerably lowers the activation barrier for the $\mathrm{Mn}$ migration needed for the phase conversion. The present structural, energetic and kinetic aspects elucidating the role of crystal water undoubtedly provide critical insight that is valuable for understanding and designing robust hydrated 2D materials for various applications.

\section{Conflicts of interest}

There are no conflicts to declare.

\section{Acknowledgements}

We acknowledge the financial support of the Korean Government through the National Research Foundation (NRF-2014R1A4A1003712, NRF-2017R1A2B3010176, NRF-2016M3D1A1021147， NRF-2015R1A2A1A15055539) and the $R \& D$ Convergence Program of the National Research Council of Science \& Technology (CAP-15-02-KBSI).

\section{Notes and references}

1 L. Croguennec and M. R. Palacin, J. Am. Chem. Soc., 2015, 137, 3140-3156.

2 M. H. Han, E. Gonzalo, G. Singh and T. Rojo, Energy Environ. Sci., 2015, 8, 81-102.

3 H. D. Yoo, I. Shterenberg, Y. Gofer, G. Gershinsky, N. Pour and D. Aurbach, Energy Environ. Sci., 2013, 6, 2265-2279.

4 J. E. Post, Proc. Natl. Acad. Sci. U. S. A., 1999, 96, 3447-3454.

5 C. R. Arias, C. Debiemme-Chouvy, C. Gabrielli, C. LabertyRobert, A. Pailleret, H. Perrot and O. Sel, J. Phys. Chem. C, 2014, 118, 26551-26559.

6 S. Bach, J. P. Pereiraramos and N. Baffier, Electrochim. Acta, 1993, 38, 1695-1698.

7 S. Bach, J. P. Pereiraramos, N. Baffier and R. Messina, Electrochim. Acta, 1991, 36, 1595-1603.

8 A. Boisset, L. Athouel, J. Jacquemin, P. Porion, T. Brousse and M. Anouti, J. Phys. Chem. C, 2013, 117, 7408-7422.

9 M. Nakayama, T. Kanaya, J. W. Lee and B. N. Popov, J. Power Sources, 2008, 179, 361-366.

10 K. W. Nam, S. Kim, S. Lee, M. Salama, I. Shterenberg, Y. Gofer, J. S. Kim, E. Yang, C. S. Park, J. S. Kim, S. S. Lee,
W. S. Chang, S. G. Doo, Y. N. Jo, Y. Jung, D. Aurbach and J. W. Choi, Nano Lett., 2015, 15, 4071-4079.

11 Y. Dai, K. Wang and J. Y. Xie, Appl. Phys. Lett., 2007, 90, 104102. 12 S. Komaba, T. Tsuchikawa, A. Ogata, N. Yabuuchi, D. Nakagawa and M. Tomita, Electrochim. Acta, 2012, 59, 455-463.

13 A. R. Armstrong, N. Dupre, A. J. Paterson, C. P. Grey and P. G. Bruce, Chem. Mater., 2004, 16, 3106-3118.

14 Y. M. Chiang, D. R. Sadoway, Y. I. Jang, B. Y. Huang and H. F. Wang, Electrochem. Solid-State Lett., 1999, 2, 107-110.

15 M. Gu, I. Belharouak, J. M. Zheng, H. M. Wu, J. Xiao, A. Genc, K. Amine, S. Thevuthasan, D. R. Baer, J. G. Zhang, N. D. Browning, J. Liu and C. M. Wang, ACS Nano, 2013, 7, 760-767.

16 J. Hong, D. H. Seo, S. W. Kim, H. Gwon, S. T. Oh and K. Kang, J. Mater. Chem., 2010, 20, 10179-10186.

17 A. Ito, K. Shoda, Y. Sato, M. Hatano, H. Horie and Y. Ohsawa, J. Power Sources, 2011, 196, 4785-4790.

18 Y. Shao-Horn, S. A. Hackney, A. R. Armstrong, P. G. Bruce, R. Gitzendanner, C. S. Johnson and M. M. Thackeray, J. Electrochem. Soc., 1999, 146, 2404-2412.

19 S. Kim, K. W. Nam, S. Lee, W. Cho, J. S. Kim, B. G. Kim, Y. Oshima, J. S. Kim, S. G. Doo, H. Chang, D. Aurbach and J. W. Choi, Angew. Chem., Int. Ed., 2015, 54, 15094-15099.

20 S. Kim, S. Lee, K. W. Nam, J. Shin, S. Y. Lim, W. Cho, K. Suzuki, Y. Oshima, M. Hirayama, R. Kanno and J. W. Choi, Chem. Mater., 2016, 28, 5488-5494.

21 K. W. Nam, S. Kim, E. Yang, Y. Jung, E. Levi, D. Aurbach and J. W. Choi, Chem. Mater., 2015, 27, 3721-3725.

22 J. B. Mitchell, W. C. Lo, A. Genc, J. LeBeau and V. Augustyn, Chem. Mater., 2017, 29, 3928-3937.

23 G. S. Gautam, P. Canepa, W. D. Richards, R. Malik and G. Ceder, Nano Lett., 2016, 16, 2426-2431.

24 A. R. Armstrong and P. G. Bruce, Nature, 1996, 381, 499-500. 25 S. Kim, X. H. Ma, S. P. Ong and G. Ceder, Phys. Chem. Chem. Phys., 2012, 14, 15571-15578.

26 J. Reed, G. Ceder and A. Van der Ven, Electrochem. Solid-State Lett., 2001, 4, A78-A81.

27 R. M. Shields, B. Temelso, K. A. Archer, T. E. Morrell and G. C. Shields, J. Phys. Chem. A, 2010, 114, 11725-11737.

28 G. Algara-Siller, O. Lehtinen, F. C. Wang, R. R. Nair, U. Kaiser, H. a. Wu, a. K. Geim and I. V. Grigorieva, Nature, 2015, 519, 443-445.

29 K. Kwac, I. Kim, T. A. Pascal, W. A. Goddard, H. G. Park and Y. Jung, J. Phys. Chem. C, 2017, 121, 16021-16028.

30 C. Adamo and V. Barone, J. Chem. Phys., 1999, 110, 6158-6170. 31 S. Grimme, J. Antony, S. Ehrlich and H. Krieg, J. Chem. Phys., 2010, 132, 154104.

32 S. Maintz, V. L. Deringer, A. L. Tchougréeff and R. Dronskowski, J. Comput. Chem., 2016, 37, 1030-1035.

33 D.-H. Seo, Y.-U. Park, S.-W. Kim, I. Park, R. A. Shakoor and K. Kang, Phys. Rev. B: Condens. Matter Mater. Phys., 2011, 83, 205127.

34 B. J. Hwang, Y. W. Tsai, D. Carlier and G. Ceder, Chem. Mater., 2003, 15, 3676-3682.

35 W. H. Baur, Acta Crystallogr., Sect. B: Struct. Crystallogr. Cryst. Chem., 1974, 30, 1195-1215. 